\title{
The Flexural Strength and Frost Resistance of Air Entrained Concrete
}

\author{
Xiuhua Zheng*1,a , Qinfei $\mathrm{Li}^{2, \mathrm{~b}}$, Jie Yuan ${ }^{3, \mathrm{c}}$, Yong Ge $\mathrm{e}^{4, \mathrm{~d}}$ \\ ${ }^{1 \sim 4}$ School of Transportation Science and Engineering, Harbin Institute of Technology, P.R. China

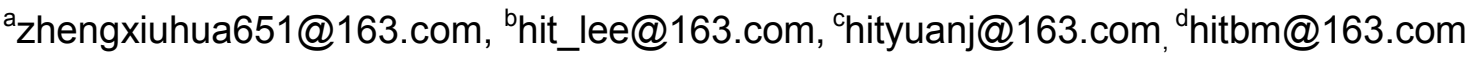 \\ ${ }^{*}$ Corresponding author. Tel/Fax: +86-451-86282191. \\ E-mail address: zhengxiuhua651@163.com (Xiuhua Zheng)
}

Key words: Flexural Strength, Frost Resistance, Freeze-thaw, Air Void Structure

\begin{abstract}
The flexural strength and frost resistance properties of air entrained concrete were tested in this study. Although the flexural strength of concrete does not change largely with increasing of air content, it still has a maximum value with air content of $4 \%$. The test results show that the frost resistance increases with increasing of air content which makes the space parameter decreasing in the harden concrete. In air entrained concrete, the total air content is not the only factor that affect the final properties of the concrete, the air void structure parameters, including void size, shape, and distribution, are key factors as well. It was found that the air void structure and the frost resistance properties were influenced by the vibration time largely. The optimized vibration time is $30 \mathrm{~s}$.
\end{abstract}

\section{Introduction}

Since the air entrainment has been discovered in 1930s [1, 2], it has been regarded as an essential part for the freeze-thaw durability of concrete. Entrained air not just improves freeze-thaw durability, but also improves the workability of concrete, reduces segregation and bleeding in freshly mixed and placed concrete, and increases pump-ability of fresh concrete [3-5]. Therefore, it leads to the reduction of water to cement ratio, which results in more impermeable concrete and a better overall resistance to aggressive agents.

The common chemical used is vinsol resin based materials [6]. In recent years, some other air entraining admixtures, such as protein additives [7], used engine oil [8], were introduced as well.

Although the air entrained concrete has been widely accepted in hydraulic or port constructions, it was not applied on the roads and bridges in China until recent years. Especially in the cold area, the frost resistance property is quite important to the durability of the concrete. Since air entraining agents can improve the freeze-thaw properties largely [9], it was considered being used in roads and bridges in recent years.

Air entrainment has not come into practice widely even today due to concrete producers difficulties with air content in concrete, and the factors affecting air entrainment, such as, temperature, cement chemistry, and supplementary cementing materials, all quite important to the final properties of the concrete. A fundamental shortcoming of air entrainment today is that only total air content is typically specified. In fact, the air-void size and distribution are also quite important to the final properties of concrete, and they were affected by those factors mentioned above. In this study, the air void structure factors were discussed in detail. 


\section{Experimentals}

The air entraining agents used in this study were DH-9 and SJ-2 (trademark), and their main chemical components were resin soap and triterpenoid saponin [4], respectively. Table 1 gives the mixture proportion of the concrete. Freeze-thaw test use the fast freeze-thaw test method.

Table1. Mixture proportion of concrete

\begin{tabular}{cccccccccccc}
\hline No. & $\begin{array}{c}\text { Fly } \\
\text { Ash } \\
(\%)\end{array}$ & W/B & $\begin{array}{r}\text { Water } \\
\left(\mathrm{kg} / \mathrm{m}^{3}\right)\end{array}$ & $\begin{array}{c}\text { Cement } \\
\left(\mathrm{kg} / \mathrm{m}^{3}\right)\end{array}$ & $\begin{array}{c}\text { Fly Ash } \\
\left(\mathrm{kg} / \mathrm{m}^{3}\right)\end{array}$ & $\begin{array}{c}\text { Sand } \\
\left(\mathrm{kg} / \mathrm{m}^{3}\right)\end{array}$ & $\begin{array}{c}\text { Aggregate UNF-5 } \\
\left(\mathrm{kg} / \mathrm{m}^{3}\right)\end{array}$ & $\begin{array}{c}\text { SJ-2 } \\
(\%)\end{array}$ & $\begin{array}{c}\text { Slump } \\
(0.01 \%)\end{array}$ & $\begin{array}{c}\text { Air } \\
\text { content } \\
(\%)\end{array}$ \\
\hline C40-I & 15 & 0.44 & 188 & 363 & 83 & 627 & 1155 & $*$ & $*$ & $*$ & $*$ \\
C40-II & 15 & 0.44 & 171 & 331 & 76 & 644 & 1184 & $*$ & $*$ & $*$ & $*$ \\
C45-I & 15 & 0.42 & 150 & 303 & 70 & 634 & 1263 & $*$ & $*$ & $*$ & $*$ \\
C60-I & 15 & 0.31 & 157 & 432 & 99 & 614 & 1141 & $*$ & $*$ & $*$ & $*$ \\
\hline
\end{tabular}

Note: The symbol, *, demonstrates that the content of SJ-2 or DH-9 is changing along with the requirements of design, and that the content of water-reducing agent is determined when the slump of fresh concrete reaches at $90 \mathrm{~mm} \sim 110 \mathrm{~mm}$. In addition, air content respectively arrives at $1 \% \sim 8 \%$ with using the SJ-2, and I and II represent respectively Grade I and Grade II Fly Ash.

\section{Results and Discussion}

Flexural Strength. The flexural strength of C40 concrete as a function of air content, with 15\% of grade I and grade II fly ash, is shown in Fig.1, as can be seen in this figure, the flexural strength does not change largely with increasing of air content when it is lower than about $7 \%$. Although the change is not very obvious, it still can be found that the flexural strength reaches the highest value when the air content is about $3 \%-4 \%$.

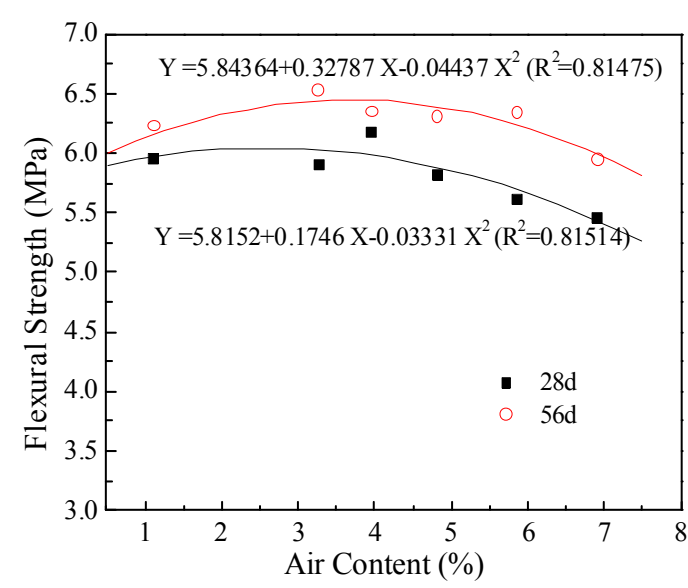

a) $15 \%$ of grade I fly ash

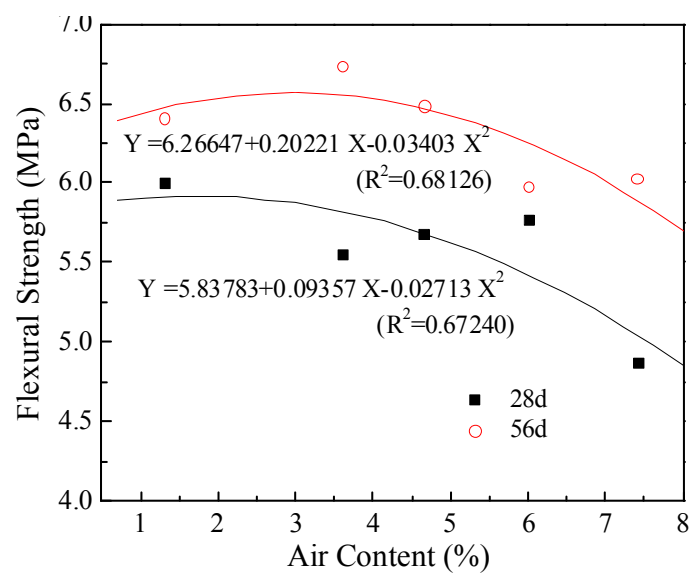

b) $15 \%$ of grade II fly ash

Fig.1 Flexural strength of $\mathrm{C} 40$ concrete as a function of air content

This phenomenon is resulted from the air voids distribution in the fresh concrete. In general, the mechanical properties of the porous materials can be predicted by the following equation [10]:

$$
\sigma=\sigma_{0} \exp (-\alpha \theta)
$$


As expressed in this equation, the mechanical properties of the porous materials should be decreased with increasing of air content. However, this is not observed in air entrained concrete when the air content is lower than about $7 \%$. In the air entrained concrete, a small quantity of air bubbles will lead to more homogeneous distribution of aggregates and decrease bleeding and segregation in concrete, and some air bubbles occupied water position in the interfaces, which results in the increasing of the flexural strength. On the other hand, under the condition of the flexural load, cracking in interior concrete is gradual growth process. When growth of cracking is coming across an air void, its energy will be weakened slightly. Therefore, air entraining process makes the specific surface increasing greatly, which increases the susceptibility to resist cracking. However, the compressive strength plays an important role in flexural strength; the more air content, the more compressive strength is declining, so that the flexural strength takes on a downward tendency.

Frost Resistance. The freezing and thawing cycles as a function of relative dynamic elastic modulus with different air content of C45 and C60 concrete are shown in Fig. 2. As demonstrated in this figure, the $\mathrm{C} 45$ concrete specimen without air entrainment fractured at the 100 freeze-thaw cycles, relative dynamic elastic modulus was $90 \%$. But in the test, the $\mathrm{C} 45$ concrete specimen fracture at 100 freeze-thaw cycles, and the C60 concrete specimen did not fracture until 300 freeze-thaw cycles. After the air was entrained into the concrete, the freeze-thaw property improved largely. The $\mathrm{C} 45$ concrete with air entrainment did not fracture after 300 freeze-thaw cycles. The C60 concrete with air content of $4.1 \%$ did not fracture until cycled 1,000 times. For the specimen with air content of $6.5 \%$, the relative dynamic elastic modulus was $96 \%$ after 1,086 freeze-thaw cycles.

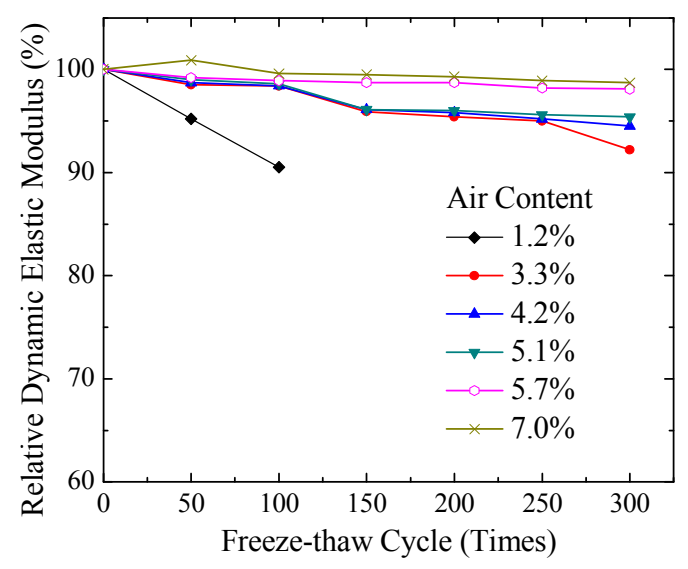

a) $\mathrm{C} 45$ concrete

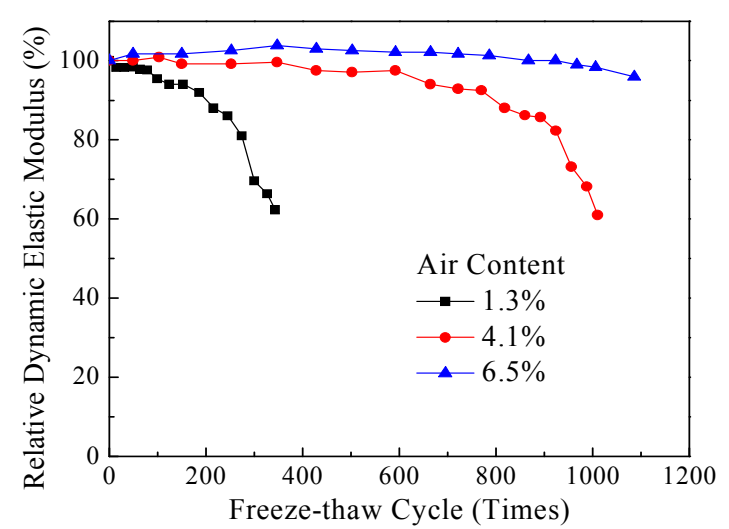

b) C60 concrete

Fig.2. Relative dynamic elastic modulus as a function of freeze - thaw cycle times

Table 2 lists the durability parameters of C45 concrete. As shown in this table, although the compressive strength decreases with increasing of air content, the frost resistance property improved largely. Generally, the durability parameters increase with increasing of air content, and decreasing of bubble space parameter. The bubble space parameter (spacing factor) decreased from $0.279 \mathrm{~mm}$ to $0.197 \mathrm{~mm}$ with the air content increase from $3.58 \%$ to $6.74 \%$, and the durability factor increased from $92.2 \%$ to $98.7 \%$. The durability factor can obtain values over $90 \%$ since the air content is higher than $3.3 \%$. While the air content is considerable, the concrete has the ability to sustain somewhat the expansion bringing by freezing water in the concrete. 
Table2. Durability parameters of C45 concrete

\begin{tabular}{ccccccc}
\hline air content(\%) & 1.2 & 3.3 & 4.2 & 5.1 & 5.7 & 7.0 \\
air content after cured(\%) & 1.74 & 3.58 & 4.12 & 4.74 & 5.4 & 6.74 \\
air bubble space parameter (mm) & 0.567 & 0.279 & 0.253 & 0.234 & 0.199 & 0.197 \\
durability parameter(\%) & 30.2 & 92.2 & 95.2 & 96.6 & 98.1 & 99.8 \\
28d compressive strength (MPa) & 48.8 & 44.1 & 42.7 & 40.4 & 38.1 & 36.5 \\
\hline
\end{tabular}

Vibration Time. In the air entrained concrete, the air void structure is another important factor that affects the final properties of the concrete. The pore structure parameters are pore size, shape, and distribution. The final properties of the air entrained concrete were different even with same air content but different air void structures. In porous materials, the pore structure can be affected by the temperature, humidity, chemical compositions or some other factors. In this study, different vibration time was used to change the pore structure factors.

Figure 3 shows the relative dynamic elastic modulus and mass loss as a function of freeze-thaw cycle times with different vibration time (vibration frequency $2850 \mathrm{~Hz} / \mathrm{min}$ ). This section selects the C45-I as the primary object shown in Table1, and uses the SJ-2 air-entraining agent to control the $6 \%$ of air content in the fresh concrete.
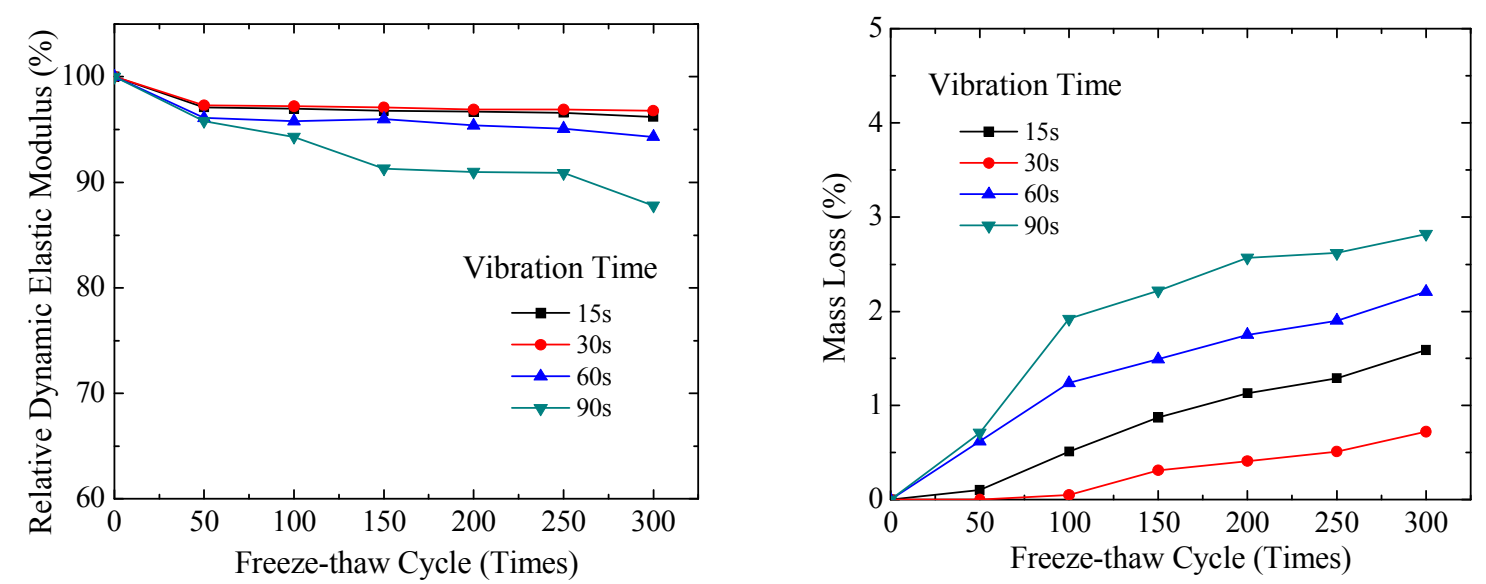

Fig .3 Relative dynamic elastic modulus and mass loss as a function of freeze-thaw cycle times with different vibration time

As can be seen in this figure, with same air content, the relative dynamic elastic modulus and mass loss increase with increasing of vibration time. This resulted from the different air void structures in concrete. The relative dynamic elastic modulus increases and mass loss decreases when the vibration time increases from $15 \mathrm{~s}$ to $30 \mathrm{~s}$. But the relative dynamic elastic modulus decreases and mass loss increases sharply if the vibration time exceeds $60 \mathrm{~s}$.

During the vibration process, air voids keep changing in the concrete. In the beginning of the vibration process, the air bubbles start to distribute homogeneously, and this leads to the increasing properties of concrete after cure, however, with increasing of vibration time, some small air voids will merge and form bigger voids, and some bigger voids will break and form new smaller voids, which leads to segregation and breaks the homogeneous state of the concrete.

Table 3 gives the air voids characterization parameters after curing 28 days. As shown in this table, the air voids structure was largely different at the top and the bottom of the specimen with different vibration time. As for the pore structure of upper section in the concrete, the optimal vibration time 
in the upper concrete is 30 seconds, less than 60 seconds. However, as shown in the specific surface, the average radium, spacing factor and pore size distribution, the optimal vibration time in the bottom concrete is 60 seconds beyond the upper section. In sum, the optimal vibration time in the concrete is 30 seconds, less than 60 seconds.

Table3. Air voids characterization parameters after curing 28 days

\begin{tabular}{|c|c|c|c|c|c|c|c|c|}
\hline \multirow{2}{*}{$\begin{array}{l}\text { vibration } \\
\text { time } \\
\text { (s) }\end{array}$} & \multirow{2}{*}{$\begin{array}{c}\text { test } \\
\text { position }\end{array}$} & \multirow{2}{*}{$\begin{array}{c}\text { specific } \\
\text { area } \\
\left(\mathrm{mm}^{2} / \mathrm{mm}^{3}\right)\end{array}$} & \multirow{2}{*}{$\begin{array}{l}\text { average } \\
\text { diameter } \\
(\mathrm{mm})\end{array}$} & \multirow{2}{*}{$\begin{array}{l}\text { bubble } \\
\text { space } \\
(\mathrm{mm})\end{array}$} & \multicolumn{4}{|c|}{$\begin{array}{l}\text { air bubble diameter distribution } \\
(\mu \mathrm{m}, \%)\end{array}$} \\
\hline & & & & & $\begin{array}{l}100 \sim \\
200\end{array}$ & $\begin{array}{c}200 \sim \\
500\end{array}$ & $\begin{array}{l}500 \sim \\
1000\end{array}$ & $>1000$ \\
\hline \multirow{2}{*}{15} & top & 29.0 & 0.104 & 0.121 & 86.1 & 11.3 & 1.7 & 0.9 \\
\hline & bottom & 32.3 & 0.0930 & 0.143 & 88.5 & 8.5 & 2.3 & 0.7 \\
\hline \multirow{2}{*}{30} & top & 32.0 & 0.0936 & 0.103 & 84.4 & 13.3 & 2.2 & 0 \\
\hline & bottom & 39.6 & 0.0758 & 0.126 & 93.2 & 5.5 & 0.5 & 0.8 \\
\hline \multirow{2}{*}{60} & top & 35.1 & 0.0855 & 0.127 & 92.0 & 6.1 & 0.9 & 0.9 \\
\hline & bottom & 46.0 & 0.0653 & 0.103 & 93.3 & 5.2 & 0.5 & 0.7 \\
\hline \multirow{2}{*}{90} & top & 31.7 & 0.0945 & 0.142 & 93.6 & 4.8 & 0 & 1.6 \\
\hline & bottom & 39.6 & 0.0758 & 0.125 & 94.0 & 4.1 & 1.6 & 0.6 \\
\hline
\end{tabular}

The parameter differences between the top and the bottom increase with increasing of vibration time. During the vibration process, the bigger bubbles tend to move upwards, displacing small bubbles, thus, the specific area difference changed obviously, and spacing factor increases from top to bottom. Since the bigger air bubbles move upward to the surface of the concrete, they will finally diminish with increasing vibration time, thus, the observed decrease in average air bubble diameter is reasonable. Vibrating is equivalently doing work on concrete, in other words, energy is added to it. In this case, some new air voids formed by this energy is coming out in fresh concrete, simultaneously, many old air void is occurring in the process of mergence and growth, and then they are collapsing or escaping from the concrete.

\section{Conclusions}

1. The flexural strength does not show obvious variation with increasing of air content, however, it still can be seen that the maximum value was obtained with air content of about $4 \%$.

2. The entrained air improved largely the freeze-thaw property .C45 concrete specimen without air entrainment fractured at the 150 freeze-thaw cycles, but the $\mathrm{C} 45$ concrete with air of $3.3 \%$ did not fracture after 300 freeze-thaw cycles.

3. The C60 concrete with air content of $4.1 \%$ did not fracture until cycled 1,000 times. For the specimen with air content of $6.5 \%$, the relative dynamic elastic modulus was $96 \%$ after 1,086 freeze-thaw cycles.

4. In air entrained concrete, the total air content is not the only factor that affects the final properties of concrete. The air void size, shape, and distribution are key factors as well. Different air void structures were realized at different durations of vibration. It was found the optimized vibration time was 30 s. 


\section{References}

[1] Chatterji S. (2003). "Freezing of air-entrained cement-based materials and specific actions of air-entrained agents" Cement Concrete Composites, Vol. 25, 759-765

[2] L. Du and Kevin J. Folliard, (2005). "Mechanisms of air entrainment in concrete" Cement and Concrete Research, Vol. 35, 1463-1471

[3] X. Ouyang, Y. Guo, and X. Qiu. (2008). "The feasibility of synthetic surfactant as an air entaining agent for the cement matrix" Construction and Building Materials, Vol. 22, 1774-1779

[4] John M. Stencel, Haiping Song, Federico Cangialosi. (2009). "Automated foam index test: Quantifiying air entraining agent addition and interactions with fly ash-cement admixtures" Cement and Concrete Research, Vol. 39, 362-370

[5] Q. Yang, et.al. (2000). "Properties of concrete with a new type of saponin air-entraining agent" Cement and Concrete Research, Vol. 30, 1313-1317

[6] Lamontagne A, Pigeon M., Pleau R, et. al.(1996). "Use of air-entraining admixtures in dry-mix shotcrete" ACI Mater. J., Vol. 93(1), 69-74

[7] Jasiczak J, Zielinski K. (2006). "Effect of protein additive on properties of mortar" Cement Concrete Composites, Vol. 28, 451-457

[8] Hamad BS, Rteil AA., El-Fadel M. (2003). "Effect of used engine oil on properties of fresh and hardened concrete" Construction and Building Materials, Vol. 17, 311-318

[9] S. Chatterji, (2003). "Freezing of air-entrained cement-based materials and specific actions of air-entraining agents" Cement and Concrete Composites Vol.25, 759-765

[10] W.Z.Shao, V.V.Ivanov, L.Zhen, et.al. (2004). "Effect of porosity and copper content on compressive strength of $\mathrm{Cu} / \mathrm{Cu} 2 \mathrm{O}$ cermet” Journal of Materials Science, Vol. 39, 731-732 